\title{
WATER DEMAND AND SUPPLY ANALYSIS USING A SPATIAL DECISION SUPPORT SYSTEM
}

\author{
E. MANOLI ${ }^{1}$ \\ G. ARAMPATZIS 1 \\ E. PISSIAS ${ }^{2}$ \\ D. XENOS 3 \\ D. ASSIMACOPOULOS 1 ,*
}

${ }^{1}$ National Technical University of Athens

School of Chemical Engineering

Heroon Polytechniou 9, Zografou Campus, 157-80, Greece

${ }^{2}$ Technological Education Institute (TEI) Athens

Faculty of Technological Applications

Ag. Spyridonos and Palikaridi, 122-10, Egaleo, Athens, Greece

${ }^{3}$ Dr. Chemical Engineer

Received: 01/06/02

Accepted: 18/06/02

* to whom all correspondence should be addressed e-mail: assim@chemeng.ntua.gr

\begin{abstract}
A prototype Spatial Decision Support System for the evaluation of water demand and supply management schemes is presented. The water basin is topologically mapped to a network of spatial objects representing the physical entities and their connections. Several GIS functions, which include data input/update, network derivation from the basin map and network building/modification are incorporated. The tool integrates suitable models for demand site requirements calculation and water allocation. Alternative scenarios can be constructed, trends and interactions of the complex water system can be analysed, strategies to solve water allocation conflicts can be evaluated and necessary infrastructure interventions can be planned in advance in order to meet water needs. The tool is demonstrated through a case study, involving the current situation and future policies for a typical Greek island.
\end{abstract}

KEY WORDS: Integrated water resources management, spatial decision support system, water allocation model.

\section{INTRODUCTION}

The need for efficient, equitable, and sustainable water allocation policies has increased in importance because of the growing scarcity and competition for water across sectors. The management process of water resources must prevent and resolve conflicts among different users. Sectoral approaches to water resource development and management have been and are still dominant (Lilburne et al., 1998; Salman et al., 2001) but there is a need for a shift towards an integrated or cross-sectoral approach to avoid fragmented and uncoordinated development of water resources (Rosegrant et al., 2000; Staudenrausch and Flugel, 2001). Water allocation policies can best be examined at a hydrological basin level, which links essential hydrologic, economic and institutional relationships as well as water uses and users and allocation decision making process. 
Integrated Water Resources Management (IWRM) has to promote the co-ordinated development and management of water, land and related resources, in order to maximize the resultant economic and social welfare in an equitable manner without compromising the sustainability of vital ecosystems (Bouwer, 2000; Albert et al., 2001). One of the central IWRM challenges is to find the right mix of management tools (Simonovic, 2000) which may vary from situation to situation. Such tools range from water resource assessment, demand regulation and regulatory instruments, social change instruments, conflict management, economic instruments and information and communication instruments. Mathematical models based on a hydrological basin spatial mapping offer the framework that allows an integrated analysis of different water-related sector elements, such as agriculture, municipal and industrial water supply and tourism. The interdisciplinary nature of water problems requires new methods to integrate the technical, economics, environmental, social, and legal aspects into a coherent environment (McKinney et al., 1999). Nowadays, there is a need for multi-objective, multipurpose and multi-facility project approach to solve water resource allocation problems. In a modeling framework, the objective function is an essential instrument to reflect the host of rules, principles and constraints in water resource management. Several objectives (economic, efficiency, social well-being, environmental, sustainability, etc.) have to be dealt with simultaneously. Spatial decision support systems (SDSS), are a class of computer systems in which the technologies of both GIS and DSS are applied to aid decision makers with problems that have a spatial dimension. GIS is a general-purpose technology for handling geographic data in digital form, offering a spatial representation of water resource systems, but currently little predictive and related analytical capacities are available for solving complex water resource planning and management problems. DSSs are interactive programs, which embed traditional water resource simulation and optimisation models, with adaptation of new approaches, to support users in semistructural or ill-structural problem solving.

In the present work a prototype SDSS for water resource management in hydrological basins is presented. A hydrological basin is topologically mapped to a network of spatial objects. The SDSS integrates suitable models for demand site requirements calculation and water allocation on the basis of alternative scenarios. The following sections give an outline of the architecture, the modelling framework and the operational details of the system. A characteristic case study, involving the current situation and future policies for a typical Greek island is presented in order and demonstrates the effectiveness of the proposed approach.

\section{TOOL ARCHITECTURE}

The structure of the developed SDSS is presented in Fig. 1. The central objective in the design of the system is to integrate data, models and decision analysis processes into a unified software package. The system was implemented within the computational environment of Microsoft Visual Basic. The GIS functionality is embedded with objects of the MapInfo MapX ActiveX component.

Users interact with the system via a GIS mapbased user-interface, which provides the functionality of inputing information and viewing of results through appropriate maps, diagrams and tables. A network representation of the hydrological basin is derived from the core database. Characteristic scenarios can be developed with the use of a network editing tool and future assumptions that affect demand, supply and hydrology can be specified. Scenarios are evaluated with the aid of a demand calculation procedure and a water allocation model. Scenarios can then be planned, simulated and evaluated and the decision-maker can undertake rational actions with respect to his objectives.

\section{Database}

The GIS database is the heart of the spatial and operational information system as well as the storage system that allows communication and intermediate storage between models and subsequent reporting modules. The object model of the database is presented in Fig. 2. The database has been developed around a geographical hierarchy, which is dictated by the very same nature of available information. The hierarchy is implemented through a collection of maps (chartographic representation) and a collection of tables with attribute data and time series (tabular representation), connected through the data-binding protocols supported by the MapX technology. 


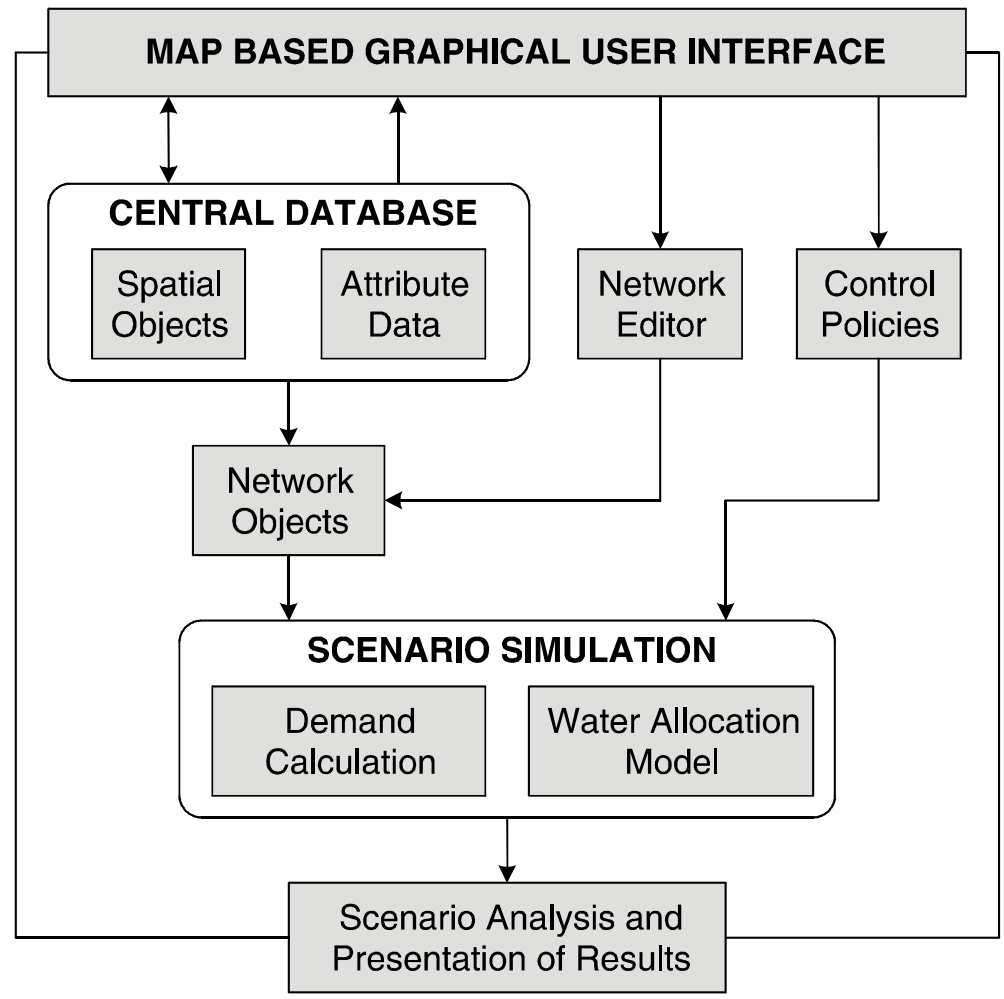

Figure 1. Architecture of the Spatial Decision Support System

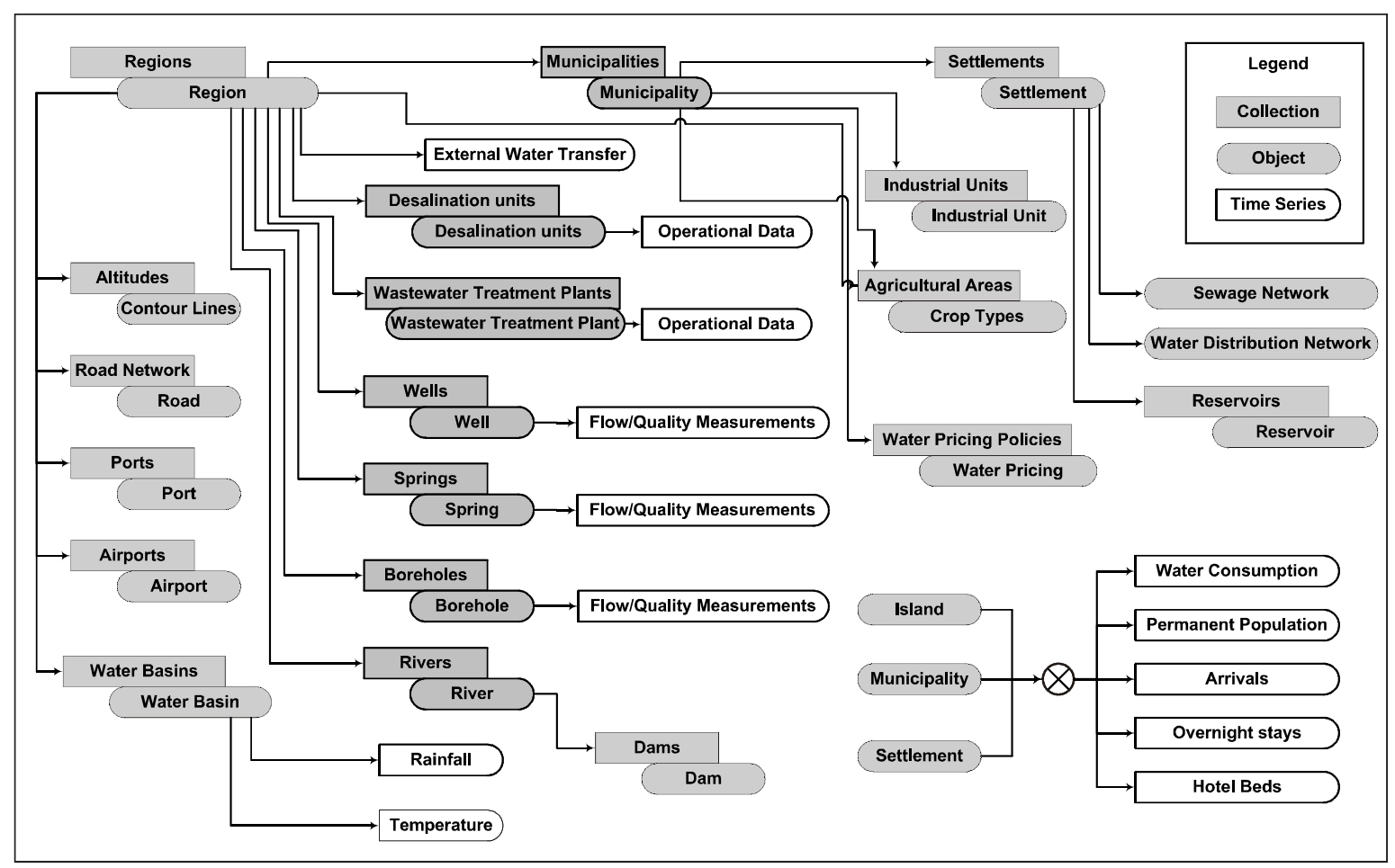

Figure 2. Central database object model and attribute data 
For each area identified as demand or supply regions, irrigated areas, industrial plants, surface and groundwater resources, storage and distribution networks are retrieved from the database. Each entity is fed with appropriate attribute data, which refer to permanent and seasonal population, agricultural water requirement, water resource availability, their monthly variation and their associated economic cost and money flows.

\section{Supply Requirements Calculation}

The estimation of the supply requirement over a specified time period is based on a hierarchical disaggregation of water demand data. The first level corresponds to demand sites. Below, specific activity levels are defined. Activity levels in the SDSS include permanent and seasonal population for settlements and towns and irrigated areas per crop type. Water demand is calculated by multiplying the overall activity level by a water consumption rate. Activity levels or water consumption rates can be projected using functions describing the specific characteristics of each demand site or activity level.

\section{Water Allocation Model}

Several methodologies have increasingly been used over the last decades for the optimal design, planning and operation of water resource systems. The two basic categories of water resource models are simulation and optimisation models (Wardlaw,1999). Mays (1996) carried out a wide review of these models. Some authors (Mannochi and Mecarelli, 1994; Reca et al., 2001) introduced economic objective functions in irrigation water allocation models. However, many of these models are not readily adaptable to the case of allocating water on a hydrological basin level.

In the present work, water allocation is achieved through a simulation model. A network representation of the hydrological basin is derived from the database (Fig. 3). Nodes represent the connection between these entities. To capture the features of the water systems' function, different types of node are incorporated. These include springs, wells, boreholes, water treatment plants, demand sites, etc. The links correspond to the man-made or natural water conduits, such as pipelines, canals, river reaches, etc. The framework of the network is constructed by connecting the nodes and links according to their physical locations in the water resource system.

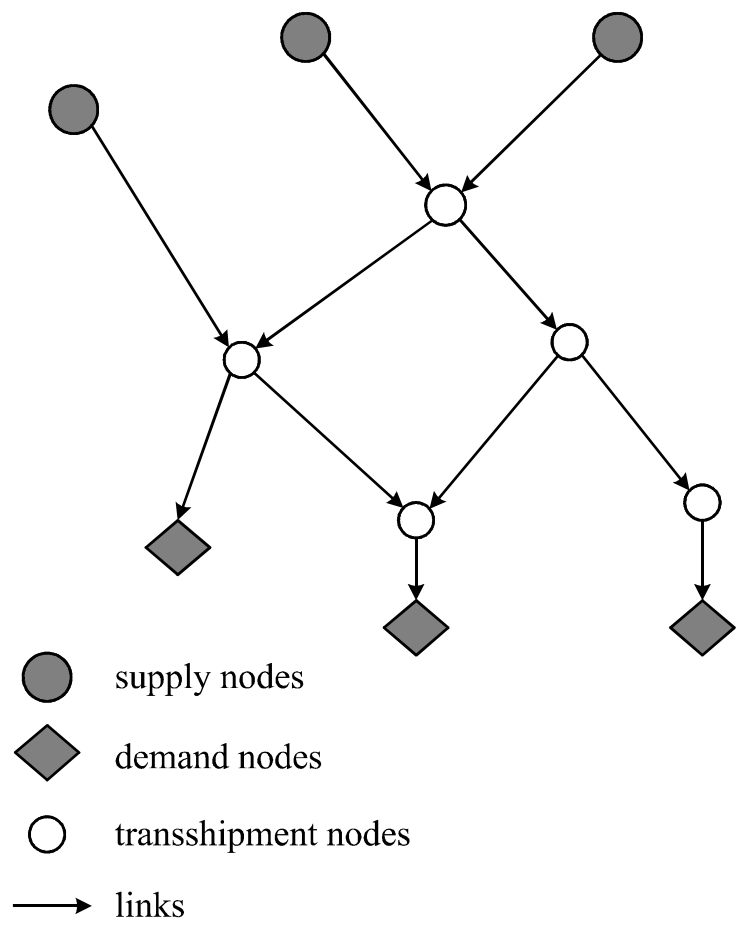

Figure 3. Network representation of a water resource system

Each node $i$ can be classified into one of the following three categories (i) supply node which is characterized by a positive monthly supply rate $s_{i}$, (ii) demand node which is characterized by a monthly demand rate $d_{i}$, and (iii) transhipment node. For each link $j$ two characteristic variables are introduced: (i) the link capacity $c_{j}$ which represents the maximum monthly flows allowed (unbounded links can be defined by assigning a sufficiently large capacity), and (ii) the link monthly flow rate $f_{j}$ (the decision variables of the problem).

In situations of water shortage, a conflict arises of how to distribute the water available at supply nodes, among the demand sites that are connected to them. The model can solve this problem using two user defined priority rules. First, competing demand sites are treated according to their priorities. Each demand site is characterized by a priority, ranged from 1 (highest priority) to 10 (lowest priority). During a water shortage, higher priority demand sites are satisfied as fully as possible. These priorities are useful in representing a system of water rights. On the other hand, supply priorities can be used when a demand site is connected to more than one supply node. These priorities are attached to the links and are useful in 
ranking the choices of a demand site for obtaining water.

The mathematical concept of the model is to find stationary solutions for each time step (month). For each time step the problem is to find the flow on the network (a set of link flows) that minimizes the water shortage on all demand nodes:

$$
\text { minimize } \sum_{\text {all demand nodes } i}\left(d_{i}-\sum_{\text {all incoming links } j} f_{j}\right)
$$

subject to the following constraints:

- Supply constraints associated with all supply nodes:

$$
\sum_{\text {all outcoming links } j} f_{j}-\sum_{\text {all incoming links } j} f_{j} \leq s_{i}
$$

- Demand constraints associated with all demand nodes:

$$
\sum_{\text {all incoming links } j} f_{j}-\sum_{\text {all outcoming links } j} f_{j} \leq d_{i}
$$

- Flow conservation constraints associated with all transhipment nodes:

$$
\sum_{\text {all outcoming links } j} f_{j}-\sum_{\text {all incoming links } j} f_{j}=0
$$

- Capacity constraints associated with all links:

$$
0 \leq f_{j} \leq c_{j}
$$

The model is solved by first constructing a reduction to a standard maxflow problem and then using a standard algorithm to solve the maxflow problem. The maxflow model applies to a basic network, i.e. a network which has exactly one source node (s) and one sink node $(\mathrm{t})$. A flow in a basic network is a set of nonnegative link flows, satisfying the conditions that no link's flow is greater than the link's capacity (Eq. 5) and that the total flow into each internal node is equal to the total flow out of that node (Eq. 4). By the above conditions, the total flow out of the source node is always equal to the total flow into the sink node. This common value is called the value of the flow. Given a basic network, the problem is to find a flow of largest possible value (a flow such as no other flow from $s$ to $t$ has larger value).

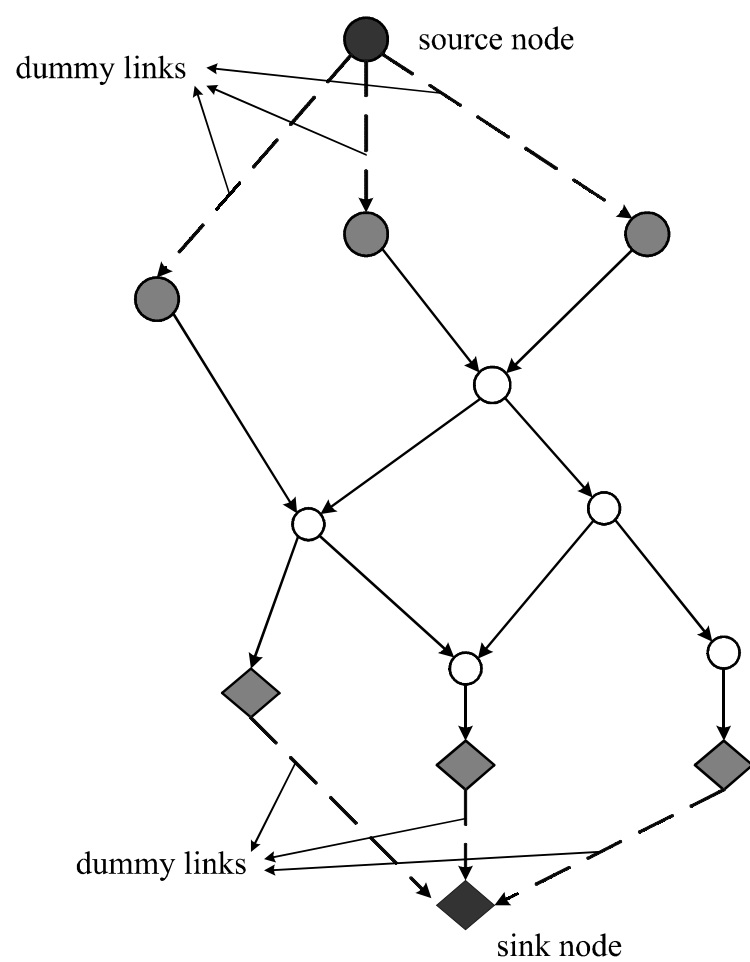

Figure 4. Network transformations

The model formulated above (Eqs. 1-5) is reduced to an equivalent maxflow problem using the following transformations (Fig. 4):

- A dummy source node (s) is added to the network.

- A dummy link from $s$ to each supply node is added to the network. The capacity of each link is set to the supply rate of the corresponding node.

- A dummy sink node ( $t$ ) is added to the network.

- A dummy link from each demand node to $t$ is added to the network. The capacity of each link is set to the demand rate of the corresponding node.

It can be easily shown that the maxflow problem to the transformed network is equivalent to the original problem. The maxflow problem is solved using the Ford-Fulkerson method, known as the Augmenting-Path Maxflow algorithm (Dolam and Aldous, 1993; Sedgewick, 2002).

To handle the priority system, an iterative goal approach is used inside each time step. The idea is first to come as close as possible to meeting the highest priority demand sites and then to try to come as close as possible to meeting the next priority demand sites but ensuring that the highest priority demand sites do not compromise. 


\section{SDSS OPERATIONAL ASPECTS}

The developed SDSS consists of three basic modules allowing for a complete representation of demand/supply scenarios. These are:

- Water demand analysis and supply requirements estimation module;

- Network editing module;

- Water allocation and water shortage estimation module.

All results are presented via fully customisable graphs and tables, in order to permit a complete evaluation of existing and proposed infrastructure for meeting demand needs.

For a demonstration of the SDSS application, a case study for the island of Syros (Fig. 5) was undertaken. Syros is located in the centre of the Cyclades complex, is the administrative centre of the prefecture and covers an area of $84 \mathrm{~km}^{2}$. Due to the important administrative role of the island, the permanent population has shown a considerable increase during the last decades. The permanent population is 20,220 inhabitants (2001 census), nearly $70 \%$ of which concentrated at the capital of the island, Ermoupolis. The rapid tourism development that has been experienced during the last 10 years has as a result the abandonment of traditional agricultural and stockbreeding activities.

Urban water consumption for the entire island in the year 2000 was about $900,000 \mathrm{~m}^{3}$ of which $25 \%$ was allocated for tourism activities. Irrigation withdrawals for the same period were estimated at $1,200,000 \mathrm{~m}^{3}$. Natural water resources are $\mathrm{lim}$ ited with scarcity problems being more acute during the arid summer period. With low rainfall (approximately $400 \mathrm{~mm} \mathrm{yr}^{-1}$ ) there are limited options for the exploitation of surface water resources. Therefore, with the exception of Ermoupolis, which relies on desalination, irrigation and urban water demand are met through the extensive exploitation of groundwater resources. The depletion of the island's aquifers and overexploitation during the summer period continue to pose a threat for economic development and preservation of future water resources.

\section{Water demand analysis and supply requirements estimation module}

The disaggregation of water use sectors derived from the database is presented in Fig. 6. Activity level data, month variation, water use rates and

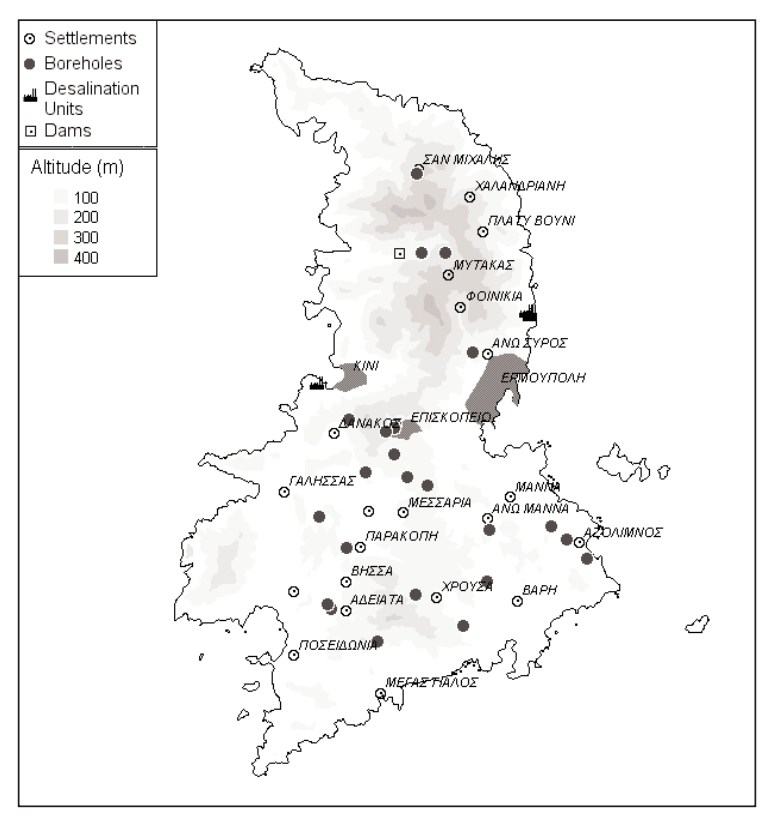

Figure 5. Syros island water resources

projection functions can be modified for each scenario introduced. For the case study undertaken, parameters used are summarized in Table 1. Estimation of irrigation water needs was based on data from the 2000 agricultural census and consumption rates for the most important crops.

Figure 7 presents the annual water demand for A. Syros and Ermoupolis agglomerations while Fig. 8 depicts the monthly variation of water demand for irrigation and domestic use as it is estimated for permanent and seasonal population needs, in 2030.

\section{Network modifying module}

The network derived from the database represents the base scenario or existing conditions. If the user wants to introduce changes into the system, he has to use the network building and editing module (Fig. 9). The module is based on the use of graphical tools for introducing nodes and drawing links, as well as related actions for appropriate modification and reshaping of the network. In all case, the user can benefit from the graphics tools supported by MapX GIS technology for performing the necessary structure and network interconnections.

Alternative water supply scenarios were developed in order to meet the water needs of Ermoupolis, A. Syros and irrigation purposes, up to the year 2030. The latter involve evaluation of 


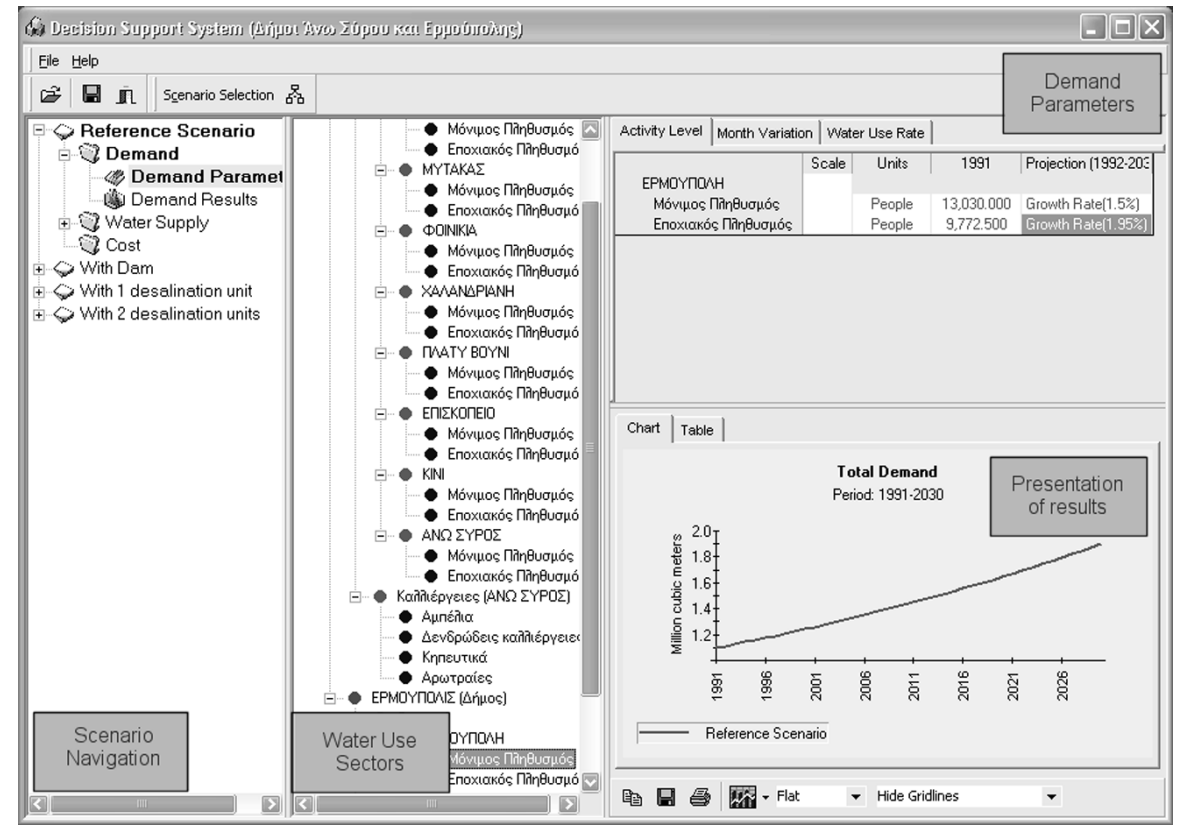

Figure 6. Demand parameters and estimation modules

Table 1. Water Demand Estimation Parameters

\begin{tabular}{|c|c|c|c|}
\hline & $\begin{array}{c}\text { Permanent } \\
\text { Population }\end{array}$ & $\begin{array}{c}\text { Seasonal } \\
\text { Population }\end{array}$ & Irrigation \\
\hline Growth Rate & $1.5 \%$ & $\begin{array}{c}3 \% \text { up to } 2010 \\
1.5 \% \text { for the period } \\
2010-2030\end{array}$ & $0 \%$ \\
\hline Consumption Rate & $150 \mathrm{l} / \mathrm{d} /$ capita & $150 \mathrm{l} / \mathrm{d} /$ capita & \\
\hline
\end{tabular}

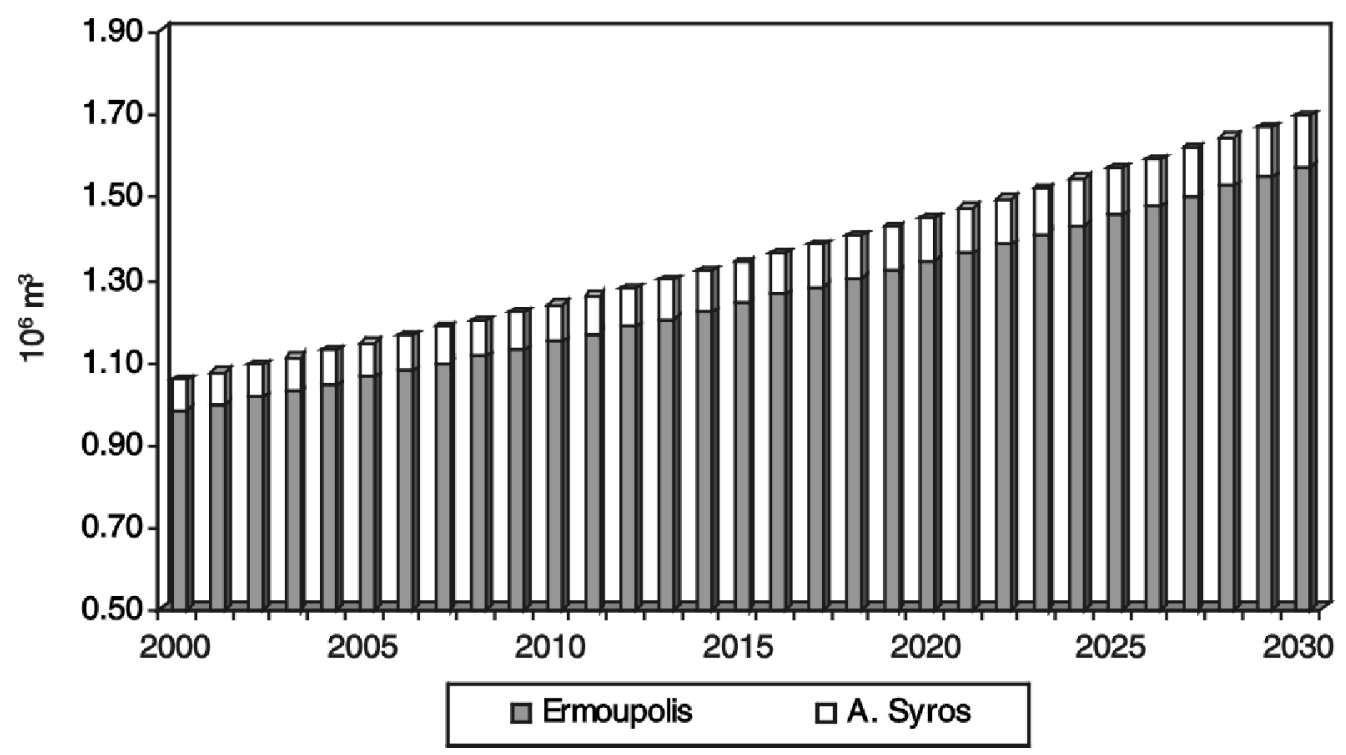

Figure 7. Annual water demand for A. Syros and Ermoupolis 


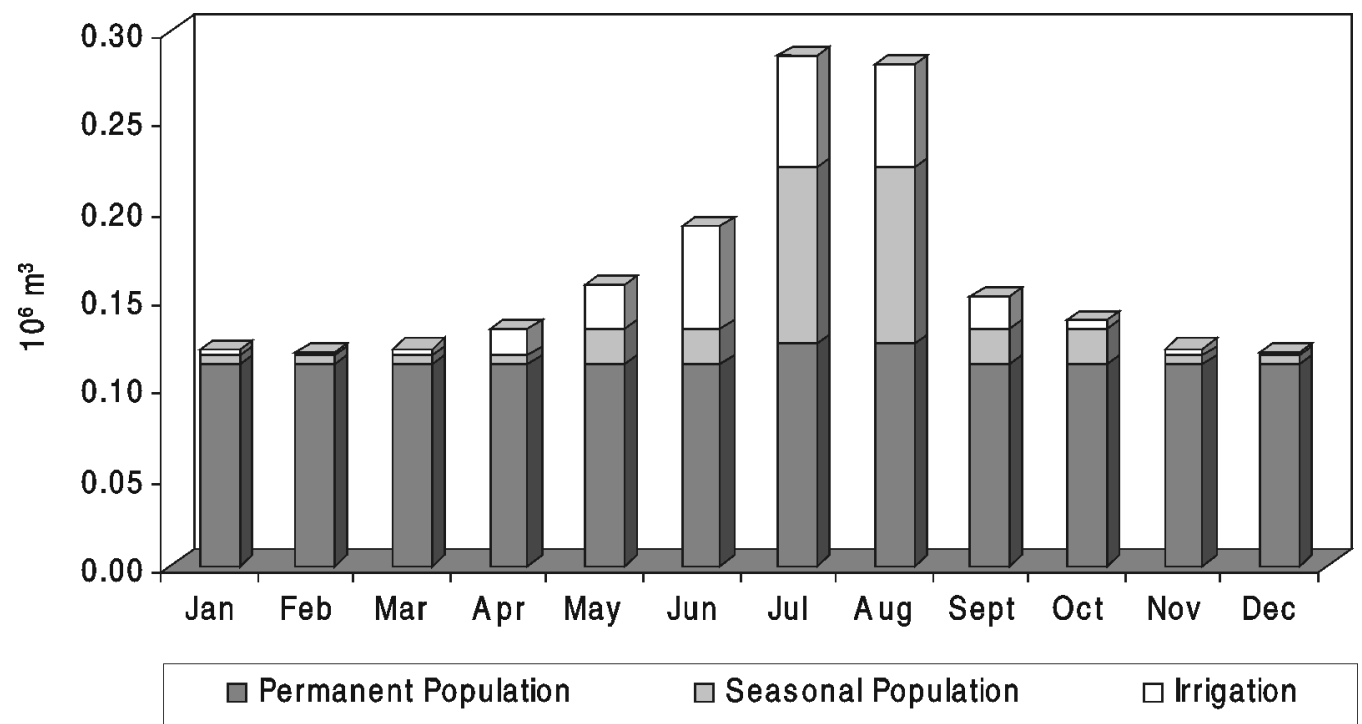

Figure 8. The monthly demand in 2030

existing infrastructure, dam construction and determination of the appropriate time horizon for other interventions such as desalination unit construction. The present situation regarding water supply is presented in Table 2.

A number of studies have proposed in the past the construction of a dam in the Aetos basin. In the scenario of the present case study, the dam is expected to be fully operational by 2005 . With a capacity of $400,000 \mathrm{~m}^{3}$ and a maximum annual withdrawal of $300,000 \mathrm{~m}^{3}$, it should primarily meet the domestic demand of A. Syros and Ermoupolis and secondarily irrigation demand. The proposed infrastructure is presented in Figs. 9 and 10.

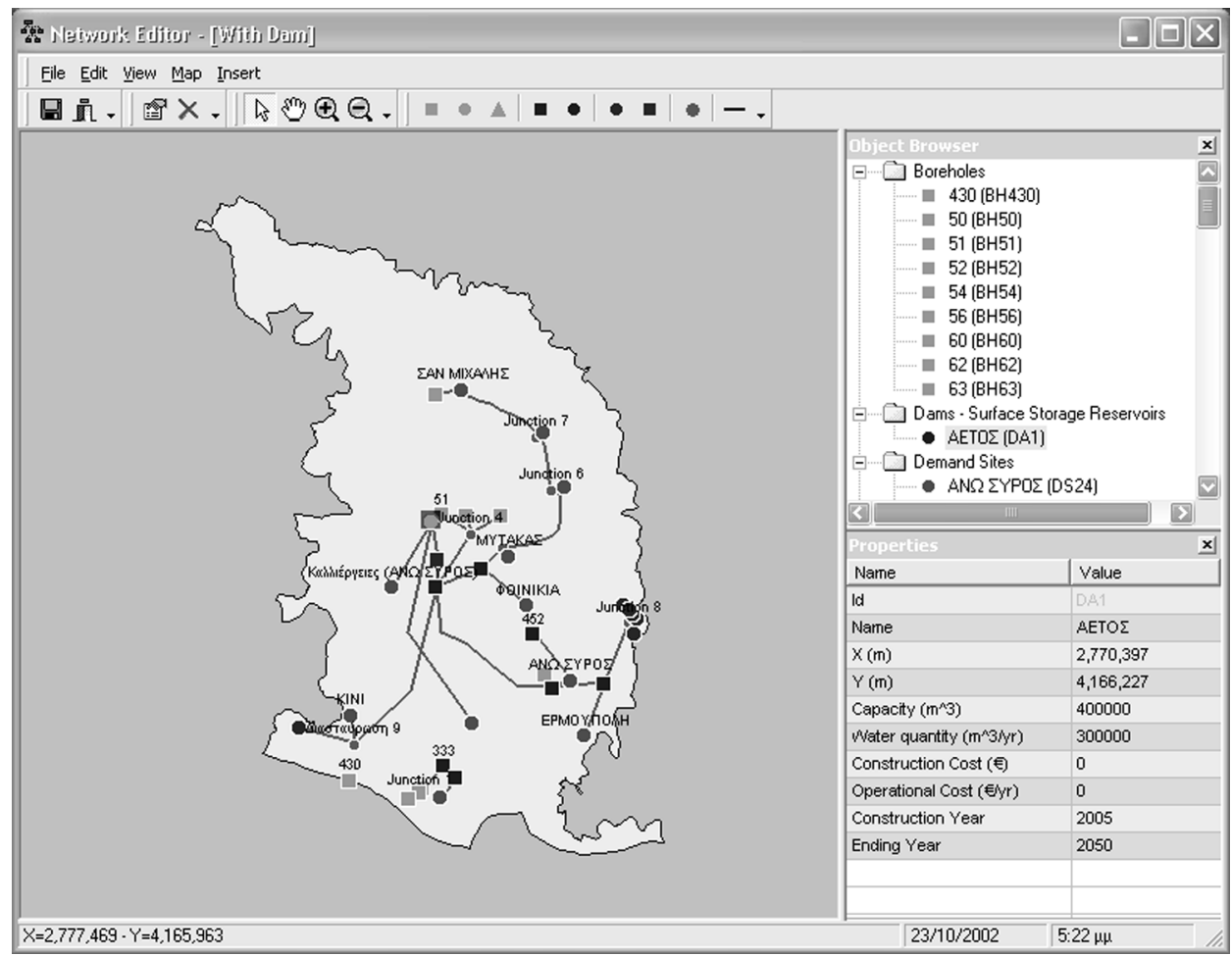

Figure 9. Network modifying module 


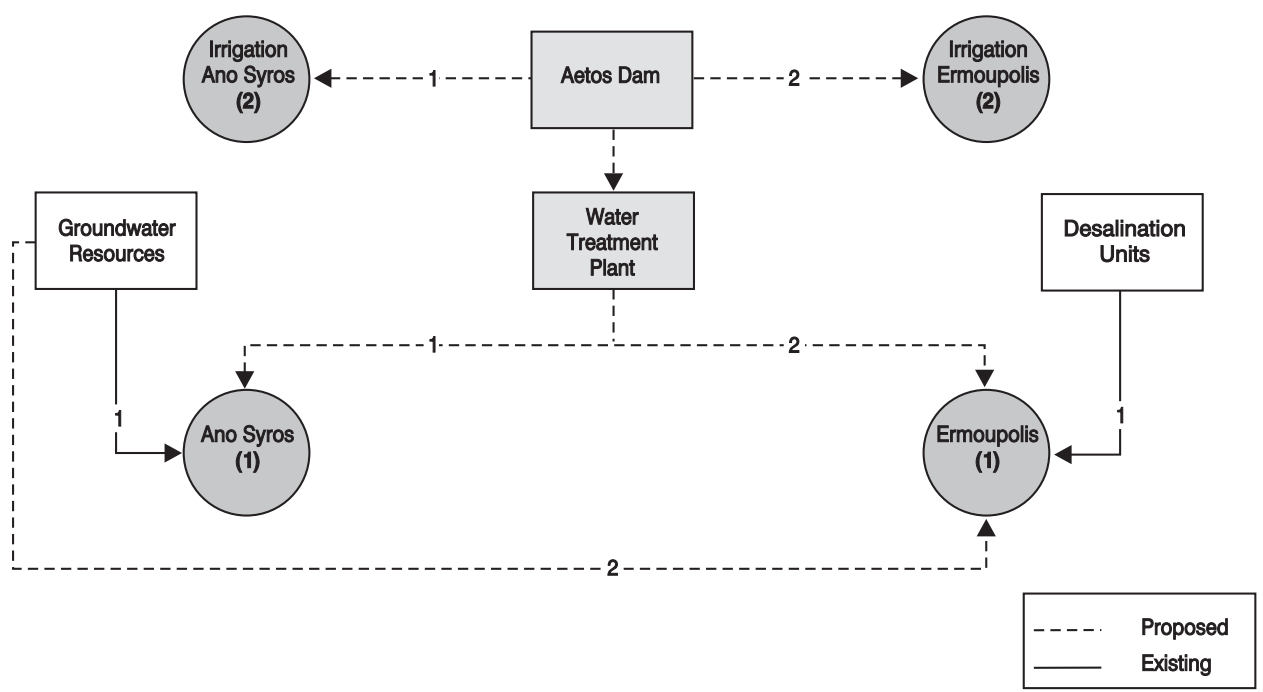

Figure 10. Demand site priorities and network configuration for Aetos dam construction

Table 2. Present water supply status for A. Syros and Ermoupolis

\begin{tabular}{|c|c|c|}
\hline & Water resources & Total water supply $\left(\mathbf{m}^{\mathbf{3}} \mathbf{d}^{-\mathbf{1}}\right)$ \\
\hline A. Syros & Boreholes & 360 \\
Ermoupolis & Desalination units & 3,460 \\
\hline
\end{tabular}

\section{Water allocation and water shortage estimation} module

The results from the water allocation module indicate that existing network infrastructure and boreholes can adequately satisfy the population of A. Syros up to the year 2022. For the period 2022 -
2030 small deficits $\left(5,000 \mathrm{~m}^{3}\right.$ in 2030$)$ are evident during the peak tourist season (July and August). However, the municipality of Ermoupolis experiences severe water shortages and cannot rely on the existing desalination units in order to meet the rapid demand growth (Fig. 11).

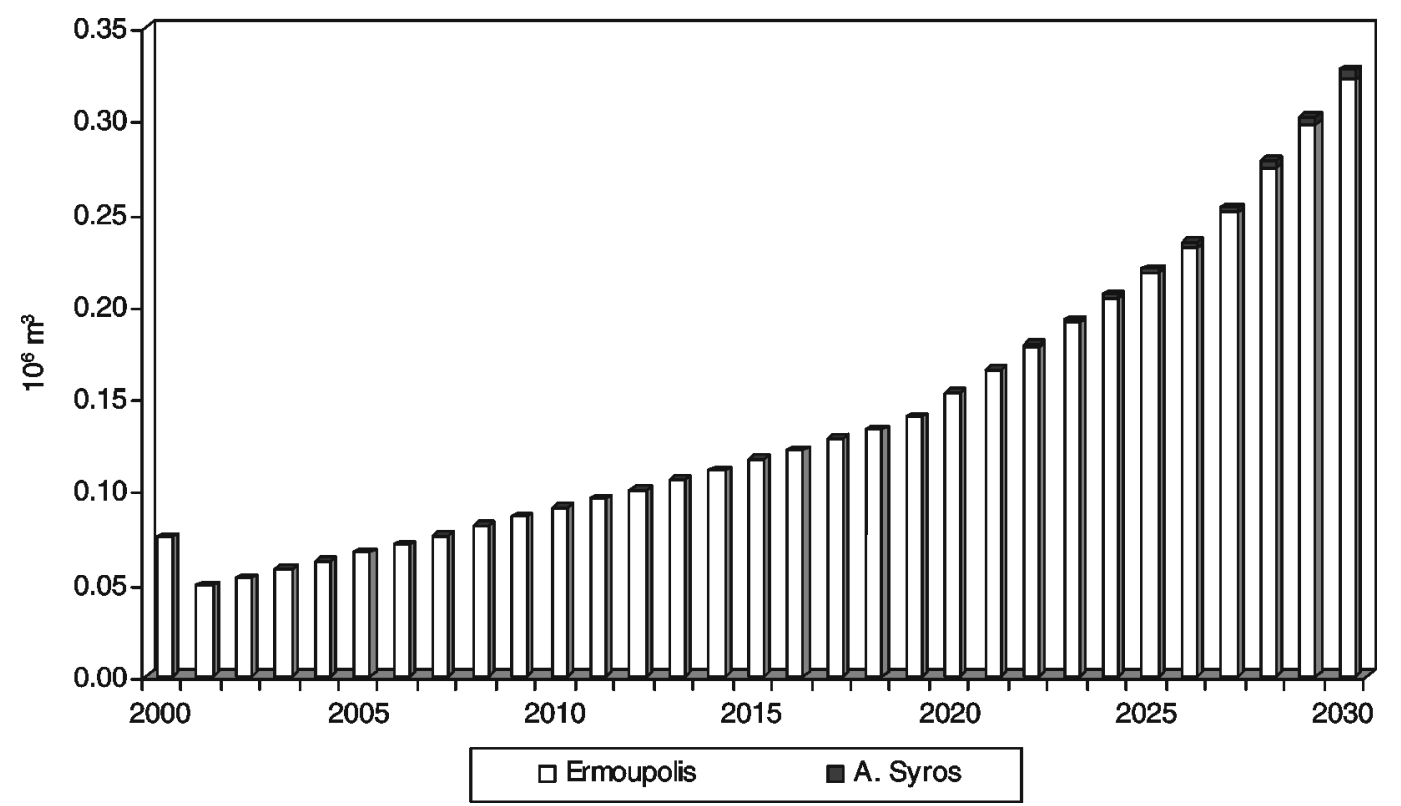

Figure 11. Evaluation of existing infrastructure for Ermoupolis and A. Syros 


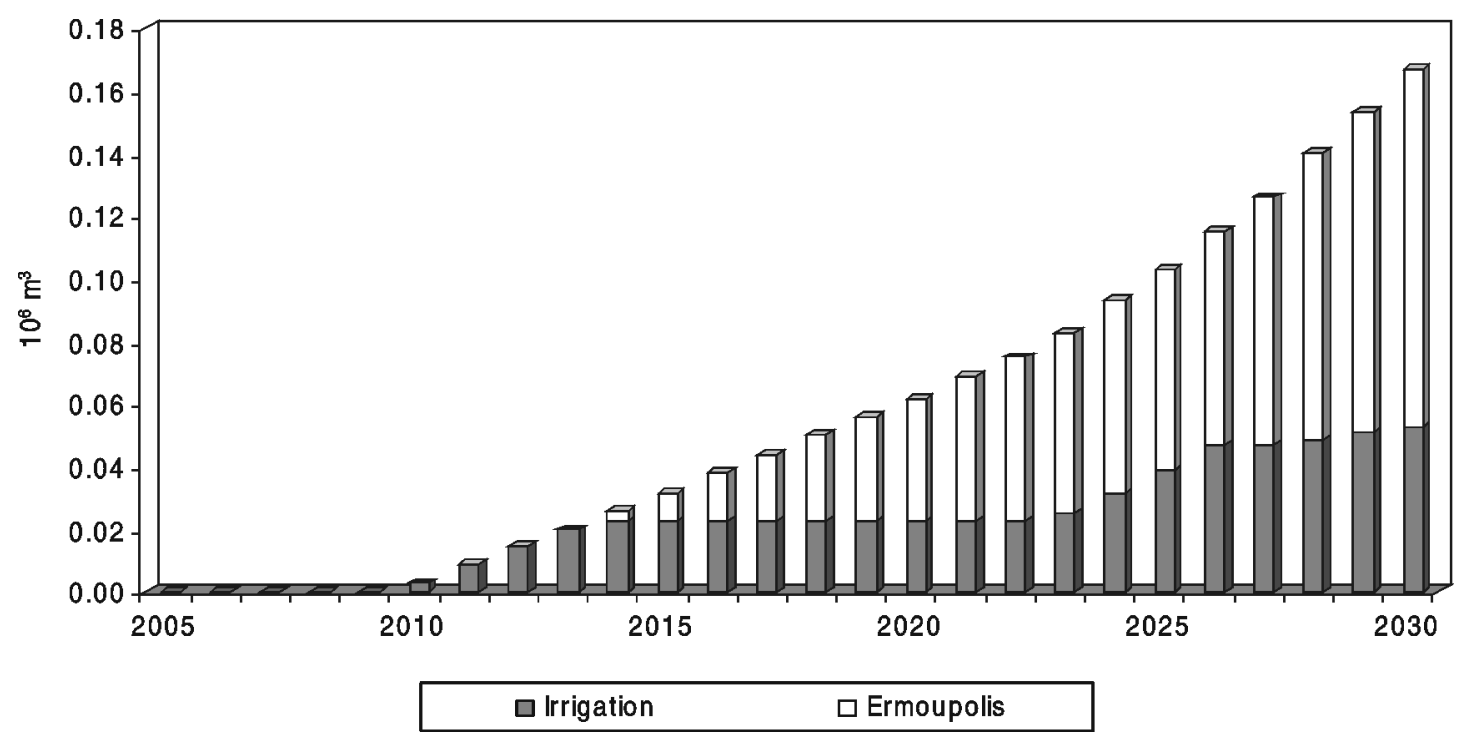

Figure 12. Water shortage in domestic and irrigation sectors after dam construction

The water shortage for the scenario with the Aetos dam construction is presented in Fig. 12. From the year 2010 a water shortage appears in the irrigation sector since water is allocated for the needs of Ermoupolis. Urban demand growth results in a direct shortage from the year 2014. What is important to notice is that the irrigation deficit is not constant as it would be expected from the estimation of irrigation needs. From the year 2024 it increases since water is withdrawed in order to serve the demand of Ermoupolis during the summer months.

As an additional water supply option, the scenario introduces a desalination unit for which according to Fig. 12, appropriate time for construction is around the year 2010 The estimation of peak month shortages and water availability indicate that with a capacity of $1,500 \mathrm{~m}^{3} \mathrm{~d}^{-1}$, the unit will be able to meet domestic demand in Ermoupolis up to the year 2025 , leaving sufficient water supply from the dam to meet irrigation needs. The unit should be rebuilt in the year 2025 with a capacity of $2,000 \mathrm{~m}^{3} \mathrm{~d}^{-1}$ in order to meet water needs up to the year 2030 .

\section{CONCLUSIONS}

A prototype spatial decision support system for the evaluation of water demand and supply management schemes has been outlined. The system integrates a spatial database of the study area and its infrastructure, tools to for network editing and specifying assumptions that affect demand, supply and hydrology, model to perform demand analysis and water allocation and components to manage and present the information. The tool was tested for a characteristic case study that demonstrated its effectiveness in analysing and supporting decision making.

\section{REFERENCES}

Albert, X., Mark, O., Babel, M.S., Gupta, A.D. and Fugl, J. (2001), Integrating Resource Management in South East Asia, Water21 October 2001, 25-30.

Bouwer, H. (2000), Integrated Water Management: Emerging Issues and Chalenges, Agricultural Water Management, 45, 217-228.

Dolam, A. and Aldous, J. (1993) Networks and Algorithms: An Introductory Approach, Wiley.

Lilburne, L, Watt, J. and Vincent, K. (1998), A Prototype DSS to Evaluate Irrigation Management Plans, Computers and Electronics in Agriculture, 21, 195-205.

Mannochi, F., Mecarelli, P. (1994), Optimization Analysis of Deficit Irrigation Systems, J. Irrig. Drain. Eng., 120 (3), 484-503.

Mays, L.W. (1996), Water Resources Handbook, McGraw-Hill, New York. 
McKinney, D.C, Cai, X, Rosegrant, M.W., Ringler, C. and Scott C.A. (1999), Modelling Water Resources Management at the Basin Level: Review and Future Directions, International Water Management Institute, SWIM Paper 6.

Reca, J., Roldan, J., Alcaide, M., Lopez, R. and Camacho, E. (2001), Optimisation Model for Water Allocation in Deficit Irrigation Systems I. Description of the Model, Agricultural Water Management, 48, 103-116.

Rosegrant, M.W., Ringler, C., McKinney, D.C., Cai, X, Keller, A. and Donoso, G (2000), Integrated EconomicHydrologic Water Modeling at the Basin Scale: the Maipo River Basin, Agricultural Economics, 24, 33-46.

Salman, A.Z., Al-Karablieh, E.K. and Fidher, F.M. (2001), An Inter-Seasonal Agricultural Water Allocation System (SAWAS), Agricultural Systems, 68, 233-252.

Sedgewick, R (2002), Algorithms in C++ Part 5: Graph Algorithms, Addison Wesley Longman.

Simonovic, S.P (2000), Tools for Water Management One View of the Future, IWRA Water International, $25,76-88$. Staudenrausch, H. and Flugel, Q.A. (2001), Development of an Integrated Water Resource Management System in Southern African Catchments, Phys. Chem. Earth, 26, 561-564.

Wardlaw R. (1999), Computer Optimisation for Better Water Allocation, Agricultural Water Management, 40, 65-70. 
